\section{Novel role for a bacterial nucleoid protein in translation of mRNAs with suboptimal ribosome-binding sites}

\author{
Hyun-Sook Park, ${ }^{1,4}$ Yngve Östberg, ${ }^{1}$ \\ Jörgen Johansson, ${ }^{1}$ E. Gerhart H. Wagner, ${ }^{2}$ \\ and Bernt Eric Uhlin ${ }^{1,3}$ \\ ${ }^{1}$ Department of Molecular Biology, The Laboratory for \\ Molecular Infection Medicine Sweden (MIMS), Umea Centre for \\ Microbial Research (UCMR), Umea University, S-90187 Umea, \\ Sweden; ${ }^{2}$ Department of Cell and Molecular Biology, \\ Biomedical Center, Uppsala University, S-75124 Uppsala, \\ Sweden
}

In Escherichia coli, the major nucleoid protein H-NS limits transcription by acting as a repressor or transcriptional silencer, presumably by its ability to close the looped chromosome domains in the nucleoid through DNA-protein-DNA bridging. Here, we demonstrate the direct involvement of $\mathrm{H}-\mathrm{NS}$ as a positive factor stimulating translation of the malT mRNA. In vitro studies showed that $\mathrm{H}-\mathrm{NS}$ facilitates a repositioning of the $30 \mathrm{~S}$ preinitiation complex on the malT mRNA. H-NS stimulation of translation depended on the AU-rich -35 to -40 region of the mRNA. Several additional examples were found demonstrating a novel function for $\mathrm{H}-\mathrm{NS}$ in translation of genes with suboptimal ribosome-binding sequences.

Supplemental material is available at http://www.genesdev.org. Received January 26, 2010; revised version accepted May 11, 2010.

The nucleoid structuring protein H-NS is a major component of the bacterial nucleoid, where it binds intrinsically curved DNA, acting as a repressor of transcription (Varshavsky et al. 1977; Lammi et al. 1984; Yamada et al. 1991; Ueguchi and Mizuno 1993). In Escherichia coli, $\mathrm{H}-\mathrm{NS}$ and the largely homologous but less abundant protein StpA are coordinately expressed (Zhang and Belfort 1992; Sondén and Uhlin 1996; Johansson and Uhlin 1999; Johansson et al. 2001). H-NS appears to be a multipurpose regulatory protein involved in the global control of gene expression in Gram-negative bacteria (Johansson et al. 1998; Schröder and Wagner 2002). Most H-NS-mediated modulation of gene expression occurs at the transcriptional level, with H-NS acting primarily as a transcriptional repressor (Falconi et al. 1993; Ueguchi et al. 1993). $\mathrm{H}-\mathrm{NS}$ has also been described as a transcriptional silencer,

[Keywords: Bacterial nucleoid; gene expression; translation; ribosomebinding sites; 5'-untranslated region]

Corresponding authors.

${ }^{3}$ E-MAIL bernt.eric.uhlin@molbiol.umu.se; FAX 46-90-772630.

${ }^{4}$ E-MAIL hyun-sook.park@molbiol.umu.se; FAX 46-90-772630.

Article is online at http://www.genesdev.org/cgi/doi/10.1101/gad.576310. and some transcriptional activators are thought to act as anti-repressors/anti-silencers, specifically by counteracting repression of genes by H-NS (Göransson et al. 1990; Uhlin 1994; Navarre et al. 2007). Some reports have also hinted at post-transcriptional H-NS functions (Yamashino et al. 1995; Brescia et al. 2004; Silva et al. 2008). Here, we report a hitherto unrecognized function of $\mathrm{H}-\mathrm{NS}$ in the direct activation of translation of certain mRNAs.

\section{Results and Discussion}

MalT is the transcriptional activator of the E. coli maltose regulon (Boos and Shuman 1998). Using malT-lacZ translational fusions, we found that expression of MalT was reduced in strains lacking H-NS and H-NS/StpA (Johansson et al. 1998). Comparison of malT-lacZ transcriptional (Alonzo et al. 1998) and translational fusions in hns and stpA mutant bacteria confirmed a translational effect (Fig. 1A; Johansson 2000). To further investigate the effect of H-NS and/or StpA on malT gene expression, we designed an in vitro translation assay system using E. coli S30 extract prepared according to Kigawa et al. (2004) from strain BSN29, which lacks both H-NS and StpA (Supplemental Fig. S1). The Shine-Dalgarno (S-D) sequence of malT (5'-UGAAGU-3') differs from consensus S-D sequences $\left(5^{\prime}\right.$-AGGAGG-3') in E. coli. Translation of MalT is known to be stimulated up to 20 -fold by an A-to-G change in the S-D sequence of malT mRNA (Chapon 1982). Replacing the wild-type GAAG with GGAG results in a 1-nucleotide (nt) shift and a stronger base-pairing interaction of the anti-S-D sequence of 16S rRNA with the S-D sequence (Supplemental Fig. S2). Equal amounts of wildtype $\left(m_{1} T_{\mathrm{WT}}\right)$ transcripts and transcripts carrying the base substitution in the S-D sequence $\left(\right.$ mal $\left._{\mathrm{P} 7}\right)$ were used in the in vitro translation system. Translation of malT $T_{\mathrm{WT}} \mathrm{mRNA}$ was stimulated by the addition of H-NS, in a dose-dependent manner (Fig. 1B, top). As expected, the level of malT $_{\mathrm{P} 7}$ mRNA translation was already efficient, and was not stimulated further by the addition of H-NS (Fig. 1B, bottom). Addition of StpA to the translation reaction had no effect (data not shown). Direct studies of MalT protein levels in bacterial cells with the malT $T_{\mathrm{WT}}$ or mal $_{\mathrm{P} 7}$ alleles on the chromosome, and with wild-type or $\Delta h n s$ alleles, established the physiological relevance of the in vitro experiments. The levels of MalT and H-NS proteins were detected by Western blot analysis (Fig. 1C). The expression of MalT from the malT $T_{\mathrm{P} 7}$ allele with the base substitution in the S-D sequence was undoubtedly H-NS-independent in vivo (Fig. 1C, lanes 4-6), verifying that the absence of H-NS-mediated stimulation in the presence of an optimal $\mathrm{S}$-D sequence is not linked to the specific conditions used in the in vitro system.

We next performed toeprint experiments to map the $3^{\prime}$ boundary of the $30 \mathrm{~S}$ ribosomal subunit on malT mRNA. Toeprints were observed at positions +15 and +16 from the malT AUG (Fig. 2, lanes 7,13). Consistent with the in vitro translation results, the toeprint signal of mal $_{\mathrm{P} 7}$ mRNA appeared to be stronger than that of mal $_{\mathrm{WT}}$ mRNA. Preincubating 30S ribosomal subunits with increasing amounts of $\mathrm{H}$-NS at $30^{\circ} \mathrm{C}$ caused the position of the toeprint signal on malT $T_{\mathrm{WT}}$ mRNA to shift 3-4 nt in the 3' direction (Fig. 2, lanes 8-10), whereas malT $T_{\mathrm{P} 7}$ mRNA toeprints showed no such shift (Fig. 2, lanes 14-16). Our results suggest that $\mathrm{H}$-NS promotes reorganization of the 
Park et al.

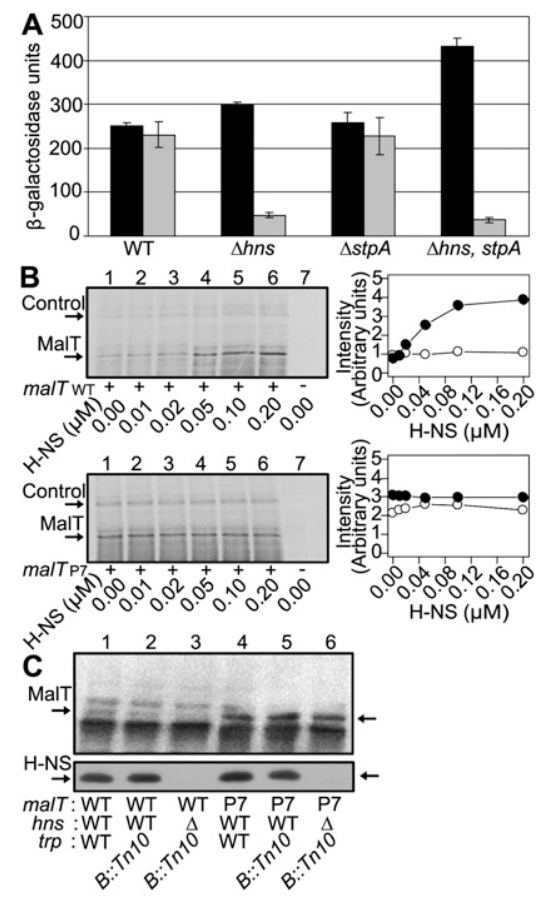

Figure 1. H-NS protein controls expression of malT in vivo and in vitro. (A) E. coli wild-type (WT) $\Delta h n s, \Delta s t p A$, and $\Delta h n s, s t p A$ strains were grown in Luria-Bertani medium at $30^{\circ} \mathrm{C}$ and harvested at 0.5 $\mathrm{OD}_{600}$. $\beta$-Galactosidase activity expressed by malT-lac $Z$ transcriptional (black) and translational (gray) fusion constructs was monitored as described in the Materials and Methods. Data shown are the mean of three independent experiments. Data for malT-lac $Z$ translational fusion constructs are from a previously published study (Johansson et al. 1998). (B) Increasing concentrations of purified H-NS were added to in vitro translation reaction mixtures with malT $_{\mathrm{WT}}$ (top) or malT $T_{\mathrm{P} 7}$ (bottom) transcripts, and were translated at $30^{\circ} \mathrm{C}$. (Left panels) Autoradiographs of in vitro products after SDSPAGE analysis. MalT and an unidentified polypeptide serving as an internal control are indicated with arrows. (Right panels) Quantified intensities (arbitrary units) of MalT $(\bullet)$ and control protein (O). (C) MalT protein levels in $E$. coli derivatives with malT $T_{\mathrm{WT}}$ or malT $_{\mathrm{P} 7}$ chromosomal alleles and effect of a $\Delta h n s$ mutation. The strains used were pop1951malT $T_{\mathrm{WT}}$ and pop1953malT $T_{\mathrm{P} 7}$ (Danot and Raibaud 1994), and their $h n s^{+}$and $\Delta h n s$ derivatives obtained after cotransduction using a $\operatorname{trp} B:: \operatorname{Tn} 10$ insertion marker for selection as described earlier (Sondén and Uhlin 1996). Western blot analyses were performed using polyclonal antibodies for detection of the MalT and H-NS proteins, respectively.

$30 S$ preinitiation complex formed on malT $T_{\mathrm{WT}}$ mRNA. Whether E. coli ribosomal proteins are specifically involved, either as part of the ribosome or functioning outside the ribosome (Park et al. 2001), remains to be investigated.

Secondary structure analysis of the malT $T_{\mathrm{WT}}$ and malT $_{\mathrm{P} 7}$ mRNA leader sequences using the programs CONTRAfold (Do et al. 2006) and Mfold (Zuker 2003) suggested that these two mRNA segments are structurally identical and fairly unstable $(-6.4 \mathrm{kcal} / \mathrm{mol})$, with relatively long stretches of single-stranded structure (Fig. 3A). To test whether binding of H-NS to the $5^{\prime}$ leader might explain the increased translational efficiency, we created different truncation mutant variants (II-VI) by removing parts of the $5^{\prime}$-untranslated region (UTR) (Fig. 3B). These mutated mRNAs were translated in vitro with or without $\mathrm{H}$-NS $(0.2 \mu \mathrm{M})$. The effect of H-NS on the level of MalT translation from variant II (lacking 21 of the $5^{\prime}$-most nucleotides) was the same as on wild-type
mRNA malT $T_{\mathrm{WT}}(\mathrm{I})$. In contrast, H-NS had no enhancing effect on variants III-V (lacking the 27, 32, and 37 5 '-proximal nucleotides, respectively). Variant VI mRNA apparently was not translated at all, regardless of the presence or absence of $\mathrm{H}-\mathrm{NS}$, suggesting that sequences upstream of the S-D sequence are required in this case for proper translation initiation (Fig. 3C). Cases in which unstructured regions upstream of a $S$-D are required for translation have been reported previously (e.g., see Darfeuille et al. 2007). We also tested the leader variants within the $5^{\prime}$-UTR of malT $_{\mathrm{P} 7}$ mRNA. All of the shortened variants except variant VI showed the same level of expression as the original malT $T_{\mathrm{P} 7}$ mRNA (I) (Fig. 3C, bottom). Taken together, these findings indicate that the unstructured 5 '-UTR contains sequences required specifically for H-NS-mediated stimulation, but not needed for translation per se. To assess if nucleotides in the region between -40 and -35 were specifically important for $\mathrm{H}$-NS-facilitated translation, we introduced the alternative nucleotides as indicated in variant $I^{\star}$ (Fig. 3B). The variant $\mathrm{I}^{\star}$ exhibited no H-NS-facilitated stimulation of translation (Fig. 3D, lanes 3,4). Translation of the malT $T_{\mathrm{P} 7}$ mRNA I* variant was independent of H-NS (Fig. 3D, lanes 7,8).

We used a gel mobility shift assay in order to test whether H-NS can bind to the malT $5^{\prime}-U T R$, and whether the -35 to -40 AU-rich sequence is required. The results suggest that $\mathrm{H}$-NS directly binds the AU-rich sequence from -35 to -40 in the $5^{\prime}$-UTR of malT $_{\mathrm{WT}}$ mRNA, as indicated by the shifted mobility of malT $_{\mathrm{WT}}$ mRNA (I), whereas no shift was observed when the variant $I^{\star}$ mRNA was tested in the gel mobility shift assay (Fig. $3 \mathrm{E}$, lanes 1-8). Our findings with different variants of the 5 '-UTR of malT mRNA suggest that specific AU-rich sequences are involved in H-NS-facilitated translation in cases of suboptimal S-D sequences. Mutation analysis implicated sequence specificity in the -40 to -35 region. The presence of certain sequences upstream of the S-D

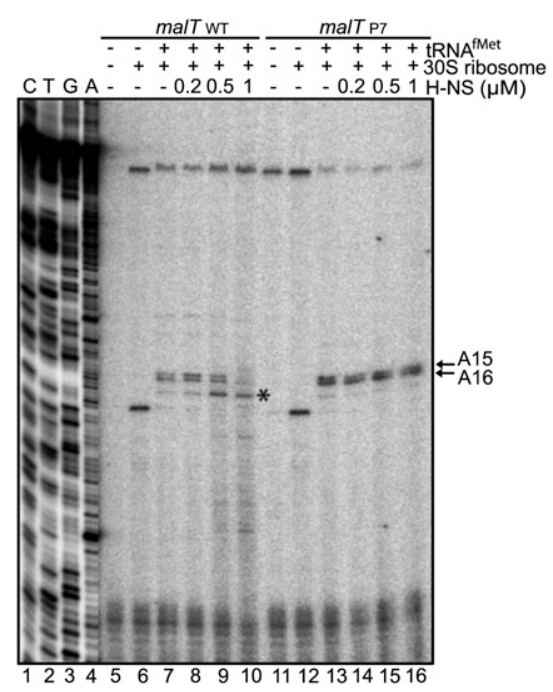

Figure 2. H-NS promotes reorganization of the $30 \mathrm{~S}$ preinitiation complex formed on malT $T_{\mathrm{WT}}$ mRNA. Increasing concentrations of purified H-NS protein were preincubated with $30 \mathrm{~S}$ ribosomal subunits, and were further incubated with $\mathrm{tRNA}^{\mathrm{fMet}}$ and malT $\mathrm{WT}_{\mathrm{WT}}$ (lanes 7-10) or malT $\mathrm{P}_{\mathrm{P} 7}$ mRNA (lanes 13-16). (Arrows) Positions of initial toeprints; (asterisk) shifted position of the mal $T_{\mathrm{WT}}$ toeprint in the presence of H-NS. (Lanes 1-4) malT DNA sequencing reaction. 


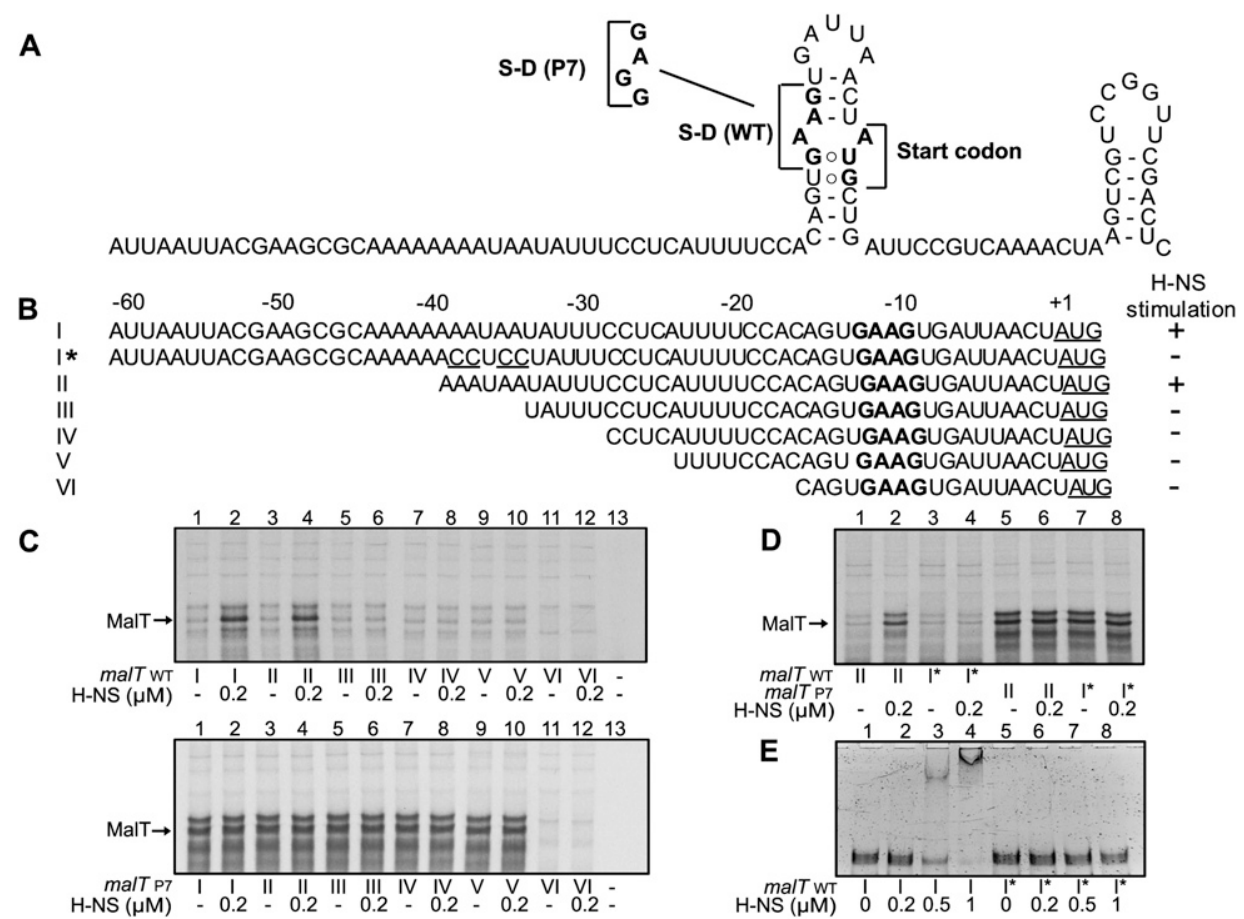

Figure 3. 5'-UTR sequences are essential for H-NS-assisted facilitation of translation of malT $\mathrm{WT}_{\mathrm{WT}} \mathrm{mRNA}$. (A) Secondary structure of malT $\mathrm{WT}_{\mathrm{WT}}$ and malT $T_{\mathrm{P} 7}$ mRNAs. (B) Wild-type (I) and shortened (II-VI) malT $T_{\mathrm{WT}}$ mRNA leader sequences. The S-D sequence is in bold, and AUG initiation codons and base substitutions made in $\mathrm{I}^{\star}$ are underlined. In each case, the $5^{\prime}$ end includes two extra nucleotides (GG; not shown here) as a consequence of the T7 promoter sequence used (Supplemental Table S2). (C) Translation of malT WT $_{\mathrm{WRNA}}($ top $)$ and malT $\mathrm{P}_{\mathrm{P} 7}$ mRNA (bottom) with wild-type and shortened leader sequences (I-VI). $(D)$ Translation of malT $T_{\mathrm{WT}}$ mRNA and malT $\mathrm{P}_{\mathrm{P}}$ mRNA variant $\mathrm{I}^{\star}$ containing four base substitutions. MalT is indicated with an arrow. (E) H-NS binding to the $5^{\prime}$-UTR of malT $T_{\mathrm{WT}}$ mRNA. The malT $\mathrm{WT}_{\mathrm{W}}$ transcripts from the wild type (I) and variant $\mathrm{I}^{\star}$ were incubated with increasing concentrations of H-NS.

sequence is known to enhance translation (Komarova et al. 2002). These "enhancers" are often AU-rich regions, occurring in exactly this -40 to -30 region found to be necessary for increased translation efficiency in the presence of H-NS in malT mRNA.

Our findings with malT prompted us to investigate whether translation of other genes with suboptimal S-D sequences would be influenced by H-NS. From the E. coli database, we identified 10 genes with only one mismatch from the S-D sequence of malT $T_{\mathrm{WT}}$ mRNA (positions -13 to -7 from AUG): dpiA, artQ, ynfF, purR, $c h b F, z n u B$, $\operatorname{lrh} A, y g j N, y h b W$, and $s f_{s} B$. RNA secondary structure predictions (CONTRAfold), and computation of their $Z$-scores (see the Supplemental Material; Freyhult et al. 2005), revealed these mRNAs to be mainly unstructured, with the exception of ygjN (Supplemental Table S1). We investigated the potential role of $\mathrm{H}-\mathrm{NS}$ in translation of $d p i A, y n f F, \operatorname{lrh} A$, and $y h b W$ mRNA. We also included $Z n u A$, as it was reported that in vivo expression of ZnuA can be increased in the presence of H-NS (Hommais et al. 2001). For each gene, codons for a His tag were included, and we also tested two mutant derivatives: one with an improved S-D sequence (GGAG; cf. malT $_{\mathrm{P} 7} \mathrm{mRNA}$ ), and the other with an abolished AUG start codon (AUG $\rightarrow$ GCG). His-tagged proteins were produced in vitro, and were detected by Western blot analysis (Fig. 4A, middle) using GroEL protein (Fig. 4A, bottom) as an internal standard. The results revealed that addition of $\mathrm{H}-\mathrm{NS}$ increased translation of wild-type $\operatorname{lrh} A, d p i A$, and $z n u A$ to levels comparable with those of mutants with improved S-D sequence (Fig. 4A, top, lanes 1-3,5-7,9-11).
Expression of yhbW was unaffected by addition of H-NS (Fig. 4A, top, lanes 13-15), whereas, in the case of ynfF, addition of $\mathrm{H}$-NS resulted in weak but detectable stimulation (Fig. 4A, top, lanes 17-19). As expected, changing AUG to GCG abolished translation of the mRNAs in all cases (Fig. 4A, top, lanes 4,8,12,16,20). These results suggest that $\mathrm{H}-\mathrm{NS}$ can increase translation of mRNAs sharing S-D features similar to those of the malT gene. Addition of H-NS to $\operatorname{lrh} A$ and $d p i A$ mRNAs with improved S-D [lrhA (GGAG) or dpiA (GGAG)] had no additional stimulatory effect on expression level (Fig. 4B, lanes 4,10). Furthermore, H-NS did not restore expression of LrhA, DpiA, MalT $\mathrm{WT}_{\mathrm{W}}$ and $\mathrm{MalT}_{\mathrm{P} 7}$ when added with the AUG-GCG variants, allowing us to exclude the possibility that H-NS affects the accuracy of translation initiation such that alternative start codons are used (Fig. 4B [lanes 6,12], C [lanes 4,8]). All of the five genes tested have AU-rich 5'-UTR sequences, but not particularly in the region between -35 and -40 ; e.g., $\operatorname{lrh} A$ and $d p i A$ have GUACC sequences at this position (Supplemental Table S1). We hypothesize that the H-NS-facilitated stimulation of translation presumably correlates with the context of the suboptimal S-D sequence, including the seemingly unstructured features of the $5^{\prime}-\mathrm{UTR}$, rather than with only AU-rich elements. Interestingly, three of the genes found here to be distinctly stimulated by H-NS at the translational level encode transcriptional regulators (malT, $\operatorname{lrh} A$, and dpiA). The direct coupling of translation to a key component of the bacterial nucleoid might ensure that translation, per se, occurs in this compartment; i.e., the physiological effect of this mechanism could be to 
A

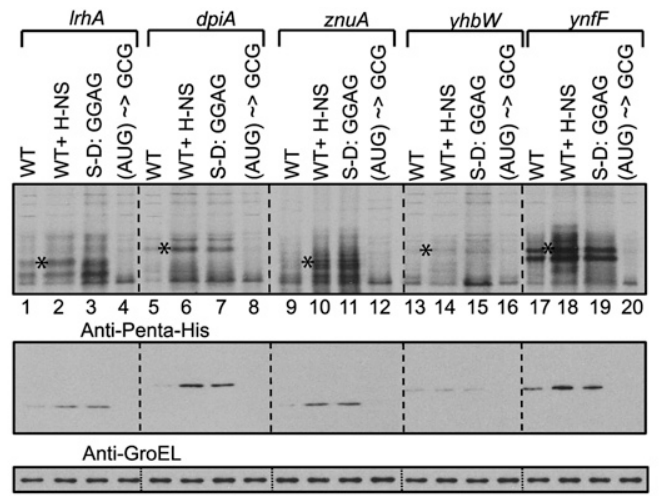

D

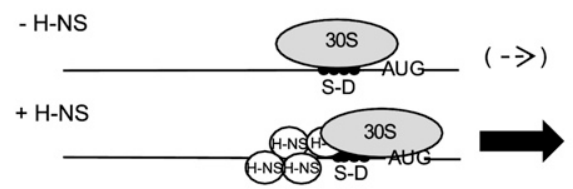

B

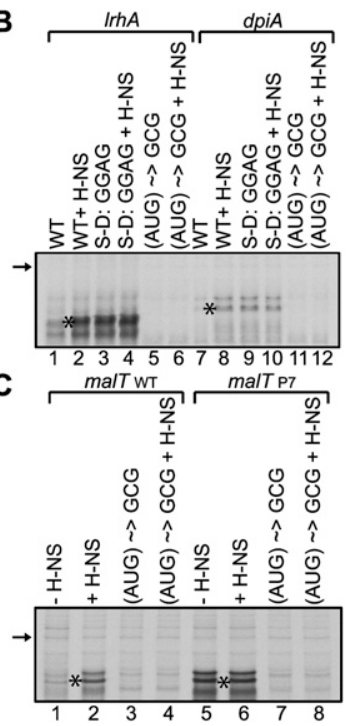

In vitro transcription and translation

DNA template for in vitro transcription was amplified by PCR from the genomic DNA of $E$. coli strains pop1951malT $_{\mathrm{WT}}$ and pop1953malT $T_{\mathrm{P} 7}$ (Danot and Raibaud 1994) using the following primer set: one forward primer containing the T7 promoter sequence, and a reverse primer containing eight codons in tandem for the amino acid histidine and a stop codon (Supplemental Fig. S1). malT $T_{\mathrm{WT}}$ or malT $\mathrm{T}_{\mathrm{P} 7}$ transcripts were obtained using the Ribomax largescale RNA production system T7 (Promega) with $5 \mu \mathrm{g}$ of DNA templates. Genomic DNA of MG1655 was used as a template to amplify genes $\operatorname{lrh} A, d p i A$, $z n u A$, yhbW, and ynfF by PCR. The nucleotide primers used to generate DNA templates for transcription are listed in Supplemental Table S2. T7-directed transcripts were translated with or without purified H-NS or StpA protein using E. coli S30 extract from BSN29 (hns, stpA). The total volume of $50 \mu \mathrm{L}$ of reaction mixtures contained $10 \mu \mathrm{L}$ of S30 extract from BSN29, $20 \mu \mathrm{L}$ of $\mathrm{S} 30$ premix without amino acids (Promega), $5 \mu \mathrm{L}$ of amino acid mixture minus methionine ( $1 \mathrm{mM}$; Promega), $60 \mu \mathrm{g}$ of RNA $(6.5 \mathrm{nM})$, and $1 \mu \mathrm{L}$ of $\left[{ }^{35} \mathrm{~S}\right]$ methionine $(1175 \mathrm{Ci} / \mathrm{mmol})$. ${ }^{35}$ S-labeled proteins were resolved on $12.5 \%$ SDSPAGE, visualized by autoradiography, and quantified with ChemiDoc XRS (Bio-Rad) using Quantity One software. The malT in vitro translation resulted in a major polypeptide product with a size of $\sim 17 \mathrm{kDa}$, and, due to presumed read-through of a UGA stop codon, an additional $\sim 18$-kDa product appeared in several experiments.

\section{Toeprint analysis}

The toeprinting assay was carried out using 30S ribosomal subunits mal $_{\mathrm{WT}}$ or malT $T_{\mathrm{P} 7} \mathrm{mRNA}$ and tRNA $^{\text {fMet }}$ as described previously (Hartz et al. 1988;

localize, and effectively limit, synthesis of the particular gene products to the nucleoid.

From our results, we suggest a repositioning mechanism in which H-NS plays a major role in forming an active initiation-competent complex, adopting an optimized position for translation initiation (Fig. 4D). In this model, H-NS would bind the unstructured mRNA of genes with suboptimal S-D sequences, allowing 30S ribosomal subunits to bind at an alternative downstream site. The 50 S subunit then joins and translation can begin; thus, H-NS functions as an auxiliary initiation factor.

In summary, we described here how the H-NS protein, earlier known as a transcriptional silencer in bacteria, can act as a positive factor in gene expression by its unexpected role in directly facilitating translation of mRNAs with suboptimal ribosome-binding sequences. It is remarkable that this protein diversifies its function, through action at both the transcriptional and translational level, to modulate gene expression both negatively and positively.

\section{Materials and methods}

\section{Protein expression and purification}

Procedures for preparation of purified H-NS and StpA proteins are described in the Supplemental Material.

Preparation of E. coli S30 extract from the BSN29 (hns, stpA) strain

The preparation of cell extract for in vitro translation is described in the Supplemental Material.
Heidrich et al. 2007). Two microliters of ${ }^{32} \mathrm{P}$-labeled primer (30 pmol) (Supplemental Table S2) in a 20- $\mu \mathrm{L}$ reaction was annealed with mRNA $(0.25 \mathrm{pmol}, 25 \mathrm{nM})$ in a $10-\mu \mathrm{L}$ reaction. Two microliters of primer/mRNA mixture was mixed with and without $30 \mathrm{~S}(4 \mathrm{pmol})$ or tRNA ${ }^{\mathrm{fMet}}$ or purified H-NS, and was incubated for $10 \mathrm{~min}$ at $30^{\circ} \mathrm{C}$. Two microliters of M-MuLV RT (Molony murine leukemia virus reverse transcriptase, Fermentas; 200 $\mathrm{U} / \mu \mathrm{L}$ ) was added to the reaction, which was further incubated at $37^{\circ} \mathrm{C}$ and stopped after $10 \mathrm{~min}$ by adding formamide loading dye $(92 \%$ formamide, $10 \mathrm{mM}$ EDTA, $0.5 \%$ bromophenol blue/xylene cyanol). The samples were heated for $5 \mathrm{~min}$ at $95^{\circ} \mathrm{C}$, centrifuged for $20 \mathrm{sec}$, and separated on a denaturing $8 \%$ polyacrylamide-urea gel. A DNA sequencing reaction was performed with the PCR product obtained from pop 1951 mal $T_{\text {WT }}$ with the same end-labeled primer. Radioactive bands were visualized with a PhosphorImager.

\section{Gel mobility shift assay}

malT $_{\mathrm{WT}}$ transcripts $(30 \mathrm{pmol})$ from the wild type (I) and the variant $\mathrm{I}^{\star}$ were heated for $2 \mathrm{~min}$ at $90^{\circ} \mathrm{C}$ and cooled to room temperature before incubation with increasing concentrations of H-NS in $10 \mu \mathrm{L}$ of binding buffer (50 mM Tris- $\mathrm{HCl}$ at $\mathrm{pH} 8.0,250 \mathrm{mM} \mathrm{NH}_{4} \mathrm{Cl}, 10 \mathrm{mM} \mathrm{MgCl}_{2}$ ). The reactions were incubated for $40 \mathrm{~min}$ at $30^{\circ} \mathrm{C}$, whereupon $1 \mu \mathrm{L}$ of $10 \times$ loading buffer ( $1 \times \mathrm{TBE}, 50 \%$ glycerol, $0.1 \%$ bromophenol blue, $0.1 \%$ xylene cyanol) was added. The samples were resolved on a $6 \%$ native polyacrylamide gel run in $0.5 \times \mathrm{TBE}$ at $4^{\circ} \mathrm{C}$, stained with ethidium bromide, and visualized by ChemiDoc XRS (Bio-Rad).

\section{Western blot analysis}

For studies of MalT protein levels in vivo, the bacterial protein extracts were separated on $6 \%$ (for MalT detection) or $12.5 \%$ (for H-NS detection) polyacrylamide gels and transferred to polyvinylidene difluoride transfer membranes by use of a semidry blotting apparatus $\left(1 \mathrm{~h}, 1 \mathrm{~mA} / \mathrm{cm}^{2}\right.$ gel). 
MalT and H-NS were detected by using anti-MalT (Johansson et al. 1998) and anti-H-NS antisera (Johansson and Uhlin 1999), respectively. Proteins from in vitro translation experiments were separated on $12.5 \%$ polyacrylamide gels and transferred to nitrocellulose membranes by electroblotting using a vertical buffer tank $\left(1 \mathrm{~h}, 1 \mathrm{~mA} / \mathrm{cm}^{2}\right.$ gel). LrhA, DpiA, ZnuA, YhbW, and YnfF were detected using purified anti-Penta His (Qiagen) monoclonal antibodies. The level of GroEL protein in the in vitro translation mixture was detected by using polyclonal purified antiGroEL (Sigma) antisera.

\section{$\beta$-Galactosidase assay}

The $\beta$-galactosidase assays were performed essentially as described before (Miller 1972).

\section{Database searches and Z-score analysis}

The sequences of $E$. coli K-12 genes used in this study were obtained via Colibri World-Wide Web Server (http://genolist.pasteur.fr/Colibri). Z-scores measure the number of standard deviations by which the minimal free energy of the native sequence deviates from the mean minimal free energy of a set of random sequences with the same dinucleotide frequency, and therefore indicate the stability of the native structure compared with the predicted structure of a random sequence with the same dinucleotide frequency (Freyhult et al. 2005). A positive or slightly negative $Z$-score means that the sequences do not have a stable structure. A $Z$-score below -3 (or at least -2 ) indicates that the structure is much more stable than the predicted structure of a random unstructured sequence.

\section{Acknowledgments}

We are indebted to E. Richet for providing strains and valuable suggestions at the early stage of this work. We thank H. Rothnie, H. Wolf-Watz, M. Ehrenberg, and G. Björk for critical reading of the manuscript; N. Heidrich for expertise in toeprint analysis; E. Freyhult for bioinformatics analysis; and M. Persson for technical assistance. H.-S.P. thanks Y. Fracheboud for support. This work was performed in the frame of the European Virtual Institute for Functional Genomics of Bacterial Pathogens (CEE LSHB-CT2005-512061), with support from the Swedish Research Council and the Swedish Foundation for International Cooperation in Research and Higher Education (STINT).

\section{References}

Alonzo S, Heyde M, Laloi P, Portalier R. 1998. Analysis of the effect exerted by extracellular $\mathrm{pH}$ on the maltose regulon in Escherichia coli K-12. Microbiology 144: 3317-3325.

Boos W, Shuman H. 1998. Maltose/maltodextrine system of Escherichia coli: Transport, metabolism, and regulation. Microbiol Mol Biol Rev 62: 204-229.

Brescia CC, Kaw MK, Sledjeski DD. 2004. The DNA binding protein H-NS binds to and alters the stability of RNA in vitro and in vivo. J Mol Biol 339: 505-514.

Chapon C. 1982. Expression of malT, the regulator of the maltose region in Escherichia coli, is limited both at transcription and translation. EMBO I 1: 369-374.

Danot O, Raibaud O. 1994. Multiple protein-DNA and protein-protein interactions are involved in transcriptional activation by MalT. Mol Microbiol 14: 335-346.

Darfeuille F, Unoson C, Vogel J, Wagner EGH. 2007. An antisense RNA inhibits translation by competing with 'standby' ribosomes. Mol Cell 26: 381-392.

Do CB, Woods DA, Batzoglou S. 2006. CONTRAfold: RNA secondary structure prediction without physics-based models. Bioinformatics 22: e90-e98. doi: 10.1093/bioinformatics/btl246.

Falconi M, Higgins NP, Spurio R, Pon CL, Gualerzi CO. 1993. Expression of the gene encoding the major bacterial nucleotide protein H-NS is subject to transcription auto-repression. Mol Microbiol 10: 273-282.

Freyhult E, Gardner PP, Moulton V. 2005. A comparison of RNA folding measures. BMC Bioinformatics 6: 241. doi: 10.1186/1471-2105-6-241.
Göransson M, Sondén B, Nilsson P, Dagberg B, Forsman K, Emanuelsson K, Uhlin BE. 1990. Transcriptional silencing and thermoregulation of gene expression in Escherichia coli. Nature 344: 682685.

Hartz D, McPheeters DS, Traut R, Gold L. 1988. Extension inhibition analysis of translation initiation complexes. Methods Enzymol 164: 419-425.

Heidrich N, Moll I, Brantl S. 2007. In vitro analysis of the interaction between the small RNA SR1 and its primary target $a h r C$ mRNA. Nucleic Acids Res 35: 4331-4346.

Hommais F, Krin E, Laurent-Winter C, Soutourina O, Malpertuy A, Le Caer JP, Danchin A, Bertin P. 2001. Large-scale monitoring of pleiotropic regulation of gene expression by the prokaryotic nucleoid-associated protein, H-NS. Mol Microbiol 40: 20-36.

Johansson J. 2000. "Regulatory interactions and global functions of the nucleoid-associated proteins H-NS and StpA in Escherichia coli." Ph.D. thesis, Umeå University, Umeå, Sweden.

Johansson J, Uhlin BE. 1999. Differential protease-mediated turnover of H-NS and StpA revealed by a mutation altering protein stability and stationary-phase survival of Escherichia coli. Proc Natl Acad Sci 96: 10776-10781.

Johansson J, Dagberg B, Richet E, Uhlin BE. 1998. H-NS and StpA proteins stimulate expression of the maltose regulon in Escherichia coli. J Bacteriol 180: 6117-6125.

Johansson J, Eriksson S, Sondén B, Wai SN, Uhlin BE. 2001. Heteromeric interactions among nucleoid-associated bacterial proteins: Localization of StpA-stabilizing regions in H-NS of Escherichia coli. J Bacteriol 183: 2343-2347.

Kigawa T, Yabuki T, Matsuda N, Matsuda T, Nakajima R, Tanaka A, Yokoyama S. 2004. Preparation of Escherichia coli cell extract for highly productive cell-free protein expression. I Struct Funct Genomics 5: 63-68.

Komarova AV, Tchufistova LS, Supina EV, Boni IV. 2002. Protein S1 counteracts the inhibitory effect of the extended Shine-Dalgarno sequence on translation. RNA 8: 1137-1147.

Lammi M, Paci M, Pon CL, Losso MA, Miano A, Pawlik RT, Gianfranceschi GL, Gualerzi CO. 1984. Proteins from the prokaryotic nucleoid: Biochemical and 1H NMR studies on three bacterial histone-like proteins. Adv Exp Med Biol 179: 467-477.

Miller JH. 1972. Experiments in molecular genetics. Cold Spring Harbor Laboratory, Cold Spring Harbor, NY.

Navarre WW, McClelland M, Libby SJ, Fang FC. 2007. Silencing of xenogenic DNA by H-NS-facilitation of lateral gene transfer in bacteria by a defense system that recognizes foreign DNA. Genes Dev 21: 1456-1471.

Park HS, Himmelbach A, Browning KS, Hohn T, Ryabova LA. 2001. A plant viral "reinitiation" factor interacts with the host translational machinery. Cell 106: 723-733.

Schröder O, Wagner R. 2002. The bacterial regulatory protein H-NS-A versatile modulator of nucleic acid structures. Biol Chem 383: 945960.

Silva AJ, Sultan SZ, Liang W, Benitez JA. 2008. Role of the histonelike nucleoid structuring protein in the regulation of rpoS and RpoS-dependent genes in Vibrio cholerae. I Bacteriol 190: 73357345.

Sondén B, Uhlin BE. 1996. Coordinated and differential expression of histone-like proteins in Escherichia coli: Regulation and function of the H-NS analog StpA. EMBO J 15: 4970-4980.

Ueguchi C, Mizuno T. 1993. The Escherichia coli nucleoid protein H-NS functions directly as a transcriptional repressor. EMBO J 12: 10391046.

Ueguchi C, Kakeda M, Mizuno T. 1993. Autoregulatory expression of the Escherichia coli hns gene encoding a nucleoid protein: H-NS functions as a repressor of its own transcription. Mol Gen Genet 236: $171-178$.

Uhlin BE. 1994. Regulation of E. coli fimbrial expression. In Fimbriae adhesion, genetics, biogenesis, and vaccines (ed. P Klemm), pp. 171177. CRC Press, Boca Raton, FL.

Varshavsky AJ, Nedospasov SA, Bakayev VV, Bakayeva TG, Georgiev GP. 1977. Histone-like proteins in the purified Escherichia coli deoxyribonucleoprotein. Nucleic Acids Res 4: 2725-2745.

Yamada H, Yoshida T, Tanaka K, Sasakawa C, Mizuno T. 1991. Molecular analysis of the Escherichia coli hns gene encoding a DNA-binding 
Park et al.

protein, which preferentially recognizes curved DNA sequences. Mol Gen Genet 230: 332-336.

Yamashino T, Ueguchi C, Mizuno T. 1995. Quantitative control of the stationary phase-specific $\sigma$ factor, $\sigma^{\mathrm{S}}$, in Escherichia coli: Involvement of the nucleoid protein H-NS. EMBO J 14: 594-602.

Zhang A, Belfort M. 1992. Nucleotide sequence of a newly-identified Escherichia coli gene, stpA, encoding an H-NS-like protein. Nucleic Acids Res 20: 6735.

Zuker M. 2003. Mfold Web server for nucleic acid folding and hybridization prediction. Nucleic Acids Res 31: 3406-3415. 


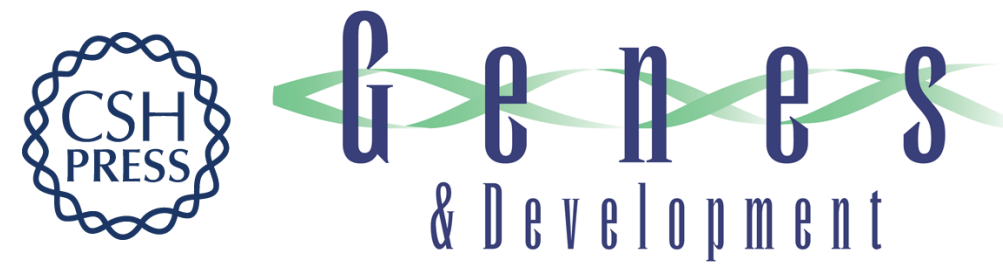

\section{Novel role for a bacterial nucleoid protein in translation of mRNAs with suboptimal ribosome-binding sites}

Hyun-Sook Park, Yngve Östberg, Jörgen Johansson, et al.

Genes Dev. 2010, 24:

Access the most recent version at doi:10.1101/gad.576310

Supplemental http://genesdev.cshlp.org/content/suppl/2010/06/25/24.13.1345.DC1
Material

References This article cites 31 articles, 7 of which can be accessed free at:

http://genesdev.cshlp.org/content/24/13/1345.full.html\#ref-list-1

License

Email Alerting

Receive free email alerts when new articles cite this article - sign up in the box at the top

Service

right corner of the article or click here.

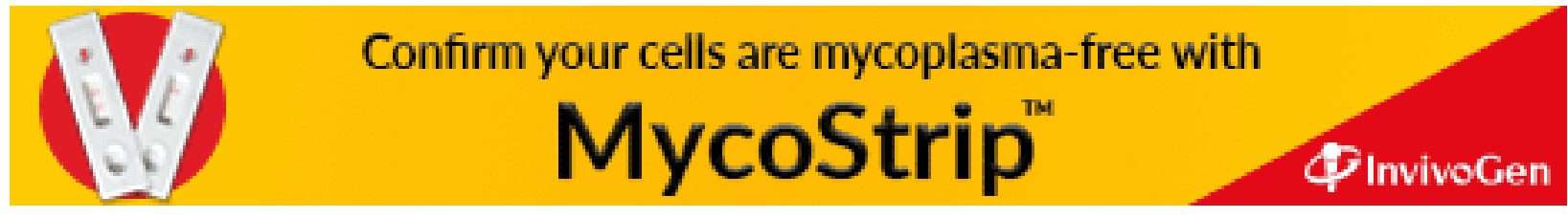

